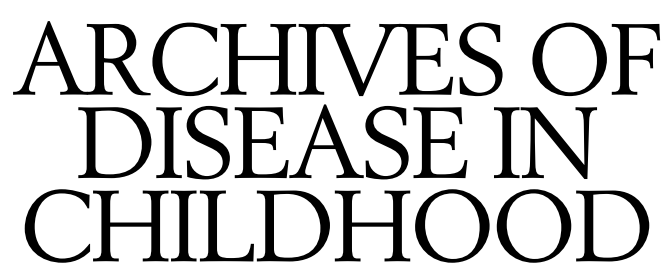

The Fournal of the Royal College of Paediatrics and Child Health

\title{
Annotations
}

\section{Birth of a formulary}

Medicines for children, published in June 1999, was prepared under the direction of the Medicines Committee, a joint committee of the Royal College of Paediatrics and Child Health (RCPCH) and the Neonatal and Paediatric Pharmacist's Group. The aim is to provide information on the drugs currently given to children for prescribers, dispensers, carers, families and children, health service managers, the Department of Health, and the courts. A secondary but equally important aim is to identify those recommended drugs that need to be subject to further clinical trials, or controlled use, or national surveillance.

An illustration of the need for such a formulary arose in 1990 when a number of Health Authorities averred that only licensed medicines should be prescribed, dispensed, and administered in their hospitals. Paediatricians wrote to the RCPCH (then the British Paediatric Association) expressing their concern. Managers are often not aware that the licence is not a licence to administer the medicine, it is a licence to sell it. The Medicines Control Agency gives market authorisation. Patients might be at a considerable disadvantage if they were only given medicines in the form and dosage the pharmaceutical industry present them, and if they were given only those drugs for which there is sufficient evidence to satisfy the Marketing Authority for a licence to be granted for the proposed usage.

Some drugs we recommend for the benefit of children have no licence at all-for example, medicines used in the treatment of children with rare metabolic diseases. The Medicines Committee's initial response to this was to prepare Drug bulletins on these drugs and send them to members. This information is now incorporated in the new formulary.

Many drugs given to children do have a licence but they are used off label. This is a complex issue. The drug may be off label for many reasons. Doctors have a duty to prescribe in the best interests of their patients. They must be well informed about the illness for which the medicine is given and the unique characteristics of each patient, as well as the properties of the drug concerned. That a Marketing Authority has scrutinised the facts and given its approval for a particular use is reassuring, but doctors must consider far more than that when they prescribe a drug.

There are many excellent sources of information on prescribing for children. We explored working within the British National Formulary framework, but the British National Formulary is constrained by the information in the datasheets and summaries of product characteristics, and could not move to where we wished to be. We looked at the current hospital formularies. They have differing styles and objectives. It is increasingly demanding to keep them up to date. So we began afresh. The Nuffield Foundation gave a generous grant to the RCPCH, which allowed us to appoint a formulary coordinator. After much discussion we elected to separate the guidance on use from the drug information, and to list the drugs in alphabetic order. We then, through our professional bodies, invited paediatricians and pharmacists to link together and produce a section on guidance with information on the drugs recommended. There have been contributions from all over the UK.

These first drafts were balanced for content and presentation and reviewed by the members of the formulary committee. A second draft then went to the reviewers who were from a range of disciplines. There were areas of disagreement, and no doubt there will be more. Identifying such territories is itself a worthwhile exercise. The text was then adjusted according to the reviewers suggestions as far as possible, and the drafts considered again by the formulary committee. A third draft was prepared, which was more concerned with format and presentation. Our aim was to be as clear, balanced, relevant, and consistent as possible.

The formulary is in four sections, guidance on prescribing, drug monographs, special foods, and indexes. In particular, the drug monographs give generic names where possible, it gives the dosages in age bands, it states what the prescriber or dispenser should know before the drug is prescribed or dispensed, and it gives the licence status. But it does not give the endless list of possible rare reactions, nor all the drug formulations available. The professional will still have to refer occasionally to the "Compendium of datasheets and summaries of product characteristics", and Martindale (The Pharmaceutical Press).

There is much more to do-for example, an abridged version to fit in residents' pockets, electronic versions so that hospitals can prepare dedicated guidance, simpler statements to compliment product information leaflets, information suitable for parents and children. And we will need to establish a databank. Over $50 \%$ of the drugs listed are either unlicensed or used outside the licensed indications. These need to be individually reviewed and identified for further trials, or controlled use, or focused surveillance.

PROFESSOR SIR DAVID HULL

Chairman, Medicines Committee (until 1999)

Department of Child Health,

University Hospital, Queen's Medical Centre,

Nottingham NG7 2 UH, UK 


\section{Williams syndrome: an update on clinical and molecular aspects}

Williams syndrome is a neurodevelopmental disorder associated with a characteristic physical and behavioural phenotype. The syndrome was described in 1961 by Williams et al who recognised a group of children with supravalvar aortic stenosis, mental retardation, and dysmorphic facial features. ${ }^{1}$ Beuren et al independently described the syndrome, noting also the friendly nature of these children, and later expanded it to include dental anomalies and peripheral pulmonary artery stenosis. ${ }^{23}$ Subsequent authors recognised the association with idiopathic hypercalcaemia.

Since the discovery in $1993^{4}$ that Williams syndrome is caused by a chromosomal microdeletion, features resulting from the deletion of contiguous genes, there has been increasing interest in trying to unravel the underlying molecular basis of the cognitive and behavioural aspects of this syndrome.

\section{Clinical history}

Infants with Williams syndrome are usually born following an uneventful pregnancy with an average birth weight of $2760 \mathrm{~g}$. In the neonatal period feeding problems are common and often accompanied by vomiting and poor weight gain. Frequent crying, sleeping problems, and constipation are also frequently reported by parents, and rectal prolapse occurs in around $10 \%$ of cases. Hernias, most commonly inguinal, occur in over a third of cases. A proportion of infants are found to have idiopathic hypercalcaemia, which is treated with a low calcium and vitamin $\mathrm{D}$ restricted diet. The underlying hormonal basis for the hypercalcaemia is not known, although there is a delayed calcitonin response to a calcium load on testing. Resolution of hypercalcaemia occurs spontaneously, usually at around 18-24 months of age.

Developmental milestones are delayed with sitting unsupported achieved at an average of 13 months and walking at 28 months. Later, difficulties in walking on uneven ground or descending stairs appear to result from defective three dimensional visual perception. After an initial period of speech delay most children with Williams syndrome tend to be overtalkative with a characteristically hoarse voice. This, with a notable overfriendliness towards strangers, has sometimes been termed a "cocktail party manner".

Hypersensitivity to certain sounds, particularly electrical appliances such drills and vacuum cleaners, fireworks or balloons popping, affects over $90 \%$ of individuals and appears to be centrally mediated. This hyperacusis, or the ability to cope with it, tends to improve with age.

Full scale intelligence quotient (IQ) is usually in the 50 s to 60s (range 40-85), although this camouflages a very uneven cognitive profile. People with Williams syndrome have relatively good verbal abilities and auditory rote memory with deficient visuospatial abilities ${ }^{56}$ and this has been termed the Williams syndrome cognitive profile (WSCP). ${ }^{78}$ While many develop quite good reading ability, few have more than very elementary numeracy.

\section{Physical phenotype}

Facial features are very characteristic: a retrousse nose with flat nasal bridge and bulbous upturned tip, a wide mouth with full lower lip, flat malar region with full cheeks, periorbital fullness, medial eyebrow flare, epicanthic folds and often stellate irides (fig 1 ). With age the face becomes thinner and coarser, and loss of subcutaneous tissue can lead to a "scraggy" appearance. The primary teeth are small, irregular, and widely spaced although in adulthood teeth tend to be crowded. Hair is usually curly and premature greying occurs in $60 \%$ of adults. The neck is long, with a prominent hyoid often apparent in adults. A characteristic posture with sloping shoulders, exaggerated lumbar lordosis, and flexion at the knees and hips may be seen. The hands are small with relatively short fingers. Squints and refractive errors are common, occurring in around $40 \%$ of patients.

There is postnatal growth retardation, with most children below the 10th centile for height. In the study by Martin et al, mean adult height was $159 \mathrm{~cm}$ for men and $147 \mathrm{~cm}$ for women. ${ }^{9}$ Failure to thrive and slim build in childhood often gives way to relative obesity in adults, with a characteristic "Hottentot" pattern of fat distribution, particularly in women. Several studies, backed by a wealth of anecdotal evidence, have demonstrated an earlier onset of puberty in Williams syndrome compared to the general population. Precocious puberty has been described in one case. $^{9 \mathrm{~A}}$

\section{Behavioural phenotype}

Poor concentration and distractibility are almost universal. Most children with Williams syndrome have poor relationships with their peers, seeking instead adult company. They tend to be outgoing, talkative, and socially uninhibited, and have high rates of preoccupations and obsessions with objects, people, and activities. Excessive anxiety about health issues and in anticipation of events is typical, as is emotional lability. Most are described by their families as friendly, caring, and attentive to the feelings of others. Aggressive behaviour is less common.

\section{Natural history}

General health is usually good. Cardiovascular abnormalities occur in around $75 \%$ of cases. The characteristic abnormalities are supravalvar aortic stenosis and peripheral pulmonary artery stenosis, although valvar and septal defects occur less commonly. Hypertension occurs in around one third of patients, and ongoing medical surveillance should include blood pressure monitoring. Renal artery stenosis has been described and cerebral and coronary artery stenoses have led to cerebrovascular accident and sudden death from myocardial infarction in some cases.

Urological abnormalities, both structural and functional, are seen with increased frequency in Williams syndrome. Nephrocalcinosis occurs secondary to hypercalcaemia and renal function may decline with age. 
Individuals with Williams syndrome tend to adopt a typical posture with sloping narrow rounded shoulders and flexion at the hips and knees. Scoliosis is seen in around $17 \%$, large joint contractures in around $15 \%$, radioulnar synostosis in $10 \%$, and recurrent patellar dislocation in 5\% of cases (Metcalfe K, unpublished data, 1998).

Most acquire independence in toileting, dressing, and washing although supervision is often needed, and very few are able to cook independently or look after finances. They continue to require substantial supervision and support in adulthood and most remain at home, in residential or in sheltered accommodation. ${ }^{10}$

\section{Genetics}

Williams syndrome usually occurs as a sporadic new dominant condition, although parent-child transmission has been reported. ${ }^{11}{ }^{12}$ As expected, there is concordance for the condition in monozygous twins and discordance in dizygous twins.

The cause is known to be the presence of a submicroscopic chromosomal deletion on one of the number 7 chromosome pair at 7q11.23. Routine chromosome analysis is usually normal and the deletion is detected by fluorescent in situ hybridisation (FISH) using a probe for the elastin gene. ${ }^{1314}$ Molecular studies have shown the microdeletion to encompass approximately $2 \mathrm{cM}$ (1.4 Mbases) of genomic DNA, the breakpoints lying approximately $1 \mathrm{cM}$ either side of the elastin gene. ${ }^{15}$ There appears to be little variability in the size of the deletion between Williams syndrome patients, as determined by polymorphic markers, despite the phenotypic variability between them. Deletions on the maternally and paternally inherited chromosomes occur with equal frequency and there does not seem to be a parental age effect. Meiotic recombination between polymorphic markers proximal and distal to the deletion has been documented, suggesting that unequal crossing over between homologous regions is the mutational mechanism in most cases. ${ }^{16}{ }^{17}$ However, the absence of recombination in other families suggests that intrachromosomal rearrangements may also occur. The presence of a genomic duplication at the deletion breakpoints may act as a hotspot for the recombination events causing Williams syndrome.

While deletion of the elastin gene in Williams syndrome can cause supravalvar aortic stenosis and other cardiovascular abnormalities, it is believed that other features of the condition are due to involvement of genes flanking elastin. A number of genes including LIM-kinase 1 (LIMK1) replication factor $\mathrm{C}$ subunit 2 (RFC2), syntaxin $1 \mathrm{~A}$ (STX1A), FZD3, GTF21, CPETR1, CPETR2, FKBP6, WSTF, WS-betaTRP, WS-bHLH, BCL7B, and transcripts including WBSCR1 and WBSCR4, are now known to lie within the deleted region. ${ }^{18-27}$ With the exception of elastin, no definite role in the Williams phenotype has been shown for these other genes to date, and indeed for many genes haploinsufficiency is unlikely to have an effect.

LIM-kinase 1 encodes a novel protein kinase, which is expressed widely in development, and its unusual structural features suggest a possible role in cell signalling. Following a paper by Frangiskakis et al implicating LIMK in visuospatial construction cognition, ${ }^{7}$ this gene was widely reported in the American press to be the first "thinking" gene. However, subsequent evidence is conflicting and the jury is still out. ${ }^{27}$

\section{Neuroanatomical studies}

Neuroanatomical studies indicate that the overall cortical volume in Williams syndrome is smaller than that of age matched normal controls. The neocerebellum, however, is normal or large and there is relative sparing of the frontal

\section{Key messages}

- Williams syndrome is caused by a microdeletion on chromosome 7 and the diagnosis can be confirmed by FISH studies

- Ongoing medical surveillance should include monitoring of blood pressure and renal function

- Williams syndrome is proving an interesting model for studying the molecular basis of cognition and behaviour

lobes and limbic system, which has been suggested as the reason for preservation of language functions and emotional responsivity. ${ }^{28}$ In physiological testing, brains of people with Williams syndrome show lack of lateralisation for activity involved with grammatical stimuli and reversal of the usual right sided function in processing of facial imaging, both processes apparently spared in Williams syndrome suggesting that functions can be devolved in the brain despite abnormal developmental patterning.

\section{Conclusion}

Although Williams syndrome is a relatively rare condition, it is proving to be an interesting model for dissecting the underlying genetic basis for behavioural and cognitive phenotypes. Hopefully, continuing molecular genetic, neurobehavioural, and neurobiological studies in the next few years will prove fruitful in increasing our understanding of such mechanisms, which have implications far wider than the syndrome itself. Better understanding of the underlying genetic defect in Williams syndrome, particularly that involved in hypercalcaemia, might also have implications for treatment of those affected and for the non-Williams syndrome form of idiopathic infantile hypercalcaemia.

K METCALFE

Department of Clinical Genetics,

St Mary's Hospital,

Manchester M13 OfH, UK

1 Williams's JCP, Barratt-Boyes BG, Lowe JB. Supravalvular aortic stenosis. Circulation 1961;24:1311-18

2 Beuren AJ, Apitz J, Harmjanz D. Supravalvular aortic stenosis in association with mental retardation and a certain facial appearance. Circulation 1962;26:1235-40.

3 Beuren AJ, Schulze C, Eberle P, Harmjanz D, Apitz J. The syndrome of supravalvular aortic stenosis, peripheral pulmonary stenosis, mental retardation and similar facial appearance. Am f Cardiol 1964;13:471-83.

4 Ewart AK, Morris CA, Atkinson D, et al. Hemizygosity at the elastin locus in a developmental disorder, Williams syndrome. Nat Genet 1993;5:11-16.

5 Udwin $\mathrm{O}$, Yule W. A cognitive and behavioural phenotype in Williams syn-

drome. F Clin Exp Neuropsychol 1991;13:232-44.
6 Bellugi U, Wang PP, Jernigan TL. Williams syndrome: an unusual neuropsychological profile. In: Broman SH, Grafman J, eds. Atypical cognitive deficits in developmental disorders:implications for brain function. Hillsdale, tive deficits in developmental disorders:implications for

7 Frangiskakis JM, Ewart AK, Morris CA, et al. LIM-kinase 1 hemizygosity implicated in impaired visuospatial constructive cognition. Cell 1996;86: 59-69.

8 Mervis CB, Robinson BF, Bertrand J, Klein BP, Armstrong SC. Williams syndrome cognitive profile [abstract]. National Williams's Syndrome Association meeting, Philadelphia 1996

Martin NDT, Snodgrass GJAI, Cohen RD. Idiopathic infantile hypercalcaemia - a continuing enigma. Arch Dis Child 1984;59:605-13.

9A Scothorn DJ, Butler MG. How common is precocious puberty in patients with Williams syndrome? Clin Dysmorphol 1997;6:91-3.

10 Davies $\mathrm{M}$, Howlin $\mathrm{P}$, Udwin $\mathrm{O}$. Independence and adaptive behaviour in adults with Williams syndrome. Am f Med Genet 1997;70:188-95.

11 Morris CA, Thomas IT, Greenberg F. Williams syndrome: autosomal dominant inheritance. Am f Med Genet 1993;47:478-81.

12 Sadler LS, Robinson LK, Verdaasdonk KR, Gingell R. The Williams syndrome: evidence for possible autosomal dominant inheritance. Am $\mathcal{F}$ Med Genet 1993;47:468-70

13 Lowery MC, Morris CA, Ewart A, et al. Strong correlation of elastin deletions detected by FISH, with Williams syndrome: evaluation of 235 patients. Am f Hum Genet 1995;57:49-53.

14 Nickerson E, Greenberg F, Keating M, McCaskill C, Shaffer LG. Deletions in the elastin gene at $7 \mathrm{q} 11.23$ occur in $\sim 90 \%$ of patients with Williams syndrome. Am f Hum Genet 1995;56:1156-61. 
15 Pérez-Jurado LA, Peoples R, Kaplan P, Hamel BCJ, Francke U. Molecular definition of the chromosome 7 deletion in Williams syndrome and parentdefinition of the chromosome 7 deletion in Williams syndrome

16 Dutly F, Schinzel A. Unequal interchromosomal rearrangements may result in elastin gene deletions causing the William-Beuren syndrome. Hum Mol Genet 1996;5:1893-8.

17 Urbán Z, Helms C, Fekete G, et al. 7q11.23 deletions in Williams syndrome arise as a consequence of unequal meiotic crossover. Am 7 Hum Genet 1996;59:958-62.

18 Tassabehji M, Metcalfe K, Fergusson WD, et al. LIM-kinase deleted in Williams syndrome. Nat Genet 1996;13:272-3.

19 Peoples R, Perez-Jurado L, Wang Y-K, Kaplan P, Francke U. The gene for replication factor C subunit2 (RFC2) is within the $7 \mathrm{q} 11.23$ Willams syndrome deletion. Am f Hum Genet 1996;58:1370-3.

20 Osborne LR, Martindale D, Scherer SW, et al. Identification of genes from a $500 \mathrm{~kb}$ region at $7 \mathrm{q} 11.23$ that is commonly deleted in Williams syndrome patients. Genomics 1996;36:328-36.

21 Wang YK, Samos CH, Peoples R, Perez-Jurado LA, Nusse R, Francke U. A novel human homologue of the Drosophila frizzled wnt receptor gene binds wingless protein and is in the Williams syndrome deletion at $7 \mathrm{q} 11.23$. Hum Mol Genet 1997;6:465-72.
22 Osborne LR, Herbrick JA, Greavette T, Heng HHQ, Tsui LA, Scherer SW. PMS2-related genes (hPMSR) flank the rearrangement breakpoints PMS2-related genes (hPMSR) flank the rearrangement breakpoin associated with Williams syndrome. 5:402-6.

23 Pérez-Jurado LA, Wang Y, Peoples R, Coloman A, Cruces J, Francke U. A duplicated gene in the breakpoint regions of the 7q11.23 Williams-Beuren syndrome deletion encodes the initiator binding protein TF11-1 and BAP135, a phosphorylation target of BTK. Hum Mol Genet 1998;7:325-34.

24 Meng X, Lu X, Morris CA, Keating MT. A novel human gene FKBP6 is deleted in Williams syndrome. Genomics 1998;52:130-7.

$25 \mathrm{Lu} \mathrm{X}$, Meng X, Morris CA, Keating MT. A novel human gene WSTF, is deleted in Williams syndrome. Genomics 1998;54:241-9.

26 Meng X, Lu X, Li Z, et al. Complete physical map of the common deletion region in Williams syndrome and identification and characterisation of three novel genes. Hum Genet 1998;103:590-9.

27 Tassabehji M, Metcalfe K, Karmiloff-Smith A, et al. Williams syndrome: use of chromosomal microdeletions as a tool to dissect cognitive and physical phenotypes. Am ₹ Hum Genet 1999;64:118-25.

28 Wang PP, Hesselink JR, Jernigan TL, Doherty S, Bellugi U. Specific neurobehavioural profile of Williams syndrome is associated with neocerebellar hemispheric preservation. Neurology 1992;42:1999-2002.

\section{Injury prevention}

Worldwide, some 300000 children die each year in road traffic crashes, a further 300000 children drown, and some 100000 die in fires. ${ }^{1}$ Many millions of children are seriously injured and hundreds of thousands sustain permanent disabilities. The public health response to this human tragedy is pitiable and raises important questions for child health professionals. Why, for example, is the death of a child following abuse taken as clear evidence of the failure of our collective efforts to protect children, whereas a child pedestrian death represents only the failure of an individual child to stop, look, and listen when crossing the road? And why did medical research "declare war" on cancer and ignore injury, when as many children die from injury as from all forms of cancer combined?

Most of the road deaths, particularly those in the developing world, involve children as pedestrians. ${ }^{2}$ In Britain, the pedestrian injury epidemic peaked in the 1930s with an average of nine deaths each day. ${ }^{3}$ Since then death rates have fallen, but not necessarily because our roads have become safer. On the contrary, the two most likely explanations for the decline in child pedestrian deaths are the massive reduction in walking that has accompanied increasing traffic volume, ${ }^{4}$ and the increased survival chances of seriously injured children from improvements in hospital care. ${ }^{5}$ There can be little doubt that in the struggle for the streets, the pedestrian lost, with tens of thousands of children killed in the process. But for most of the world the battles are just beginning. Like so many Western epidemics, the pedestrian injury epidemic is now being exported to the developing world. European and North American car markets are reaching saturation point and motor manufacturers are looking east. The road death epidemic in China is only just beginning, but already an estimated 29000 children are killed on the roads each year, ${ }^{1}$ and the epidemic will generate a mountain of disability. It is estimated that by 2020 road traffic accidents will be the third leading cause of disability adjusted life years (DALY) worldwide, and the second leading cause of DALYs in the demographically developing countries. ${ }^{6}$

An epidemic of this scale demands an appropriate and timely public health response. It is a matter of urgency that effective strategies are identified for the prevention of road traffic accidents, drowning, fire deaths, and other leading causes of injury, and for the treatment and rehabilitation of injured victims, particularly in low income countries. A logical first step would be to find out what we already know about the effectiveness of injury prevention and injury management by conducting systematic reviews of control- led intervention studies, and of case-control and cohort studies where no intervention studies are available. The Cochrane Injuries Group, an international network that prepares, maintains, and promotes the accessibility of systematic reviews of the effectiveness of interventions in the prevention, treatment, and rehabilitation of injury has been established to facilitate this process. ${ }^{7}$ To date, findings from systematic reviews include the demonstration that random breath testing reduces road deaths, ${ }^{8}$ that pool fencing reduces the risk of drowning, ${ }^{9}$ and that albumin infusion for hypovolaemia following trauma is of no proved benefit and may even increase the risk of death. ${ }^{10}$

The effectiveness of some prevention strategies is not in doubt, but for many mechanisms of injury the value of preventive measures remain uncertain, and large scale randomised controlled trials are required to determine their effectiveness. For a problem as common as injury, even moderate intervention effects would be important. However, to detect reliably moderate effects, both moderate biases and moderate random errors must be avoided. ${ }^{11}$ Injury prevention trials must therefore be large enough to avoid moderate random errors and should be designed in such a way that moderate biases are avoided. Some injury prevention interventions cannot be implemented separately for each individual and individual level randomised controlled trials will not be possible. Evaluation of these strategies requires community intervention trials, and recent developments in the methodology of cluster randomised controlled trials will facilitate these. ${ }^{12}$ Probably the main obstacles to the conduct of such studies are political rather than methodological: first the importance of random allocation in the unbiased assessment of effectiveness is not widely appreciated in areas such as transport, housing, and education; second, injury research is grossly underfunded compared with other health problems. ${ }^{13}$

The identification of effective injury prevention interventions is necessary but not sufficient to prevent childhood injuries. Many injury prevention strategies require structural change and will encounter strong opposition from vested interests. The strategy for overcoming structural barriers to child health is advocacy. Advocacy is structural therapeutics, which, to date British paediatricians have shown a notable reluctance to prescribe. ${ }^{14}$ But there are encouraging signs that things are now changing, as evidenced by the support by the Royal College of Paediatrics and Child Health for the Road Traffic Reduction (UK Targets) Bill. ${ }^{15}$ Striving to make a better world for 
children does not require a choice between science and activism. It requires both.

IAN ROBERTS

Child Health Monitoring Unit, CAROLYN DIGUISEPPI

Department of Epidemiology and Public Health,

Institute of Child Health,

30 Guilford Street, London WC1N 1EH, UK

email:Ian.Roberts@ich.ucl.ac.uk

1 Murray CJL, Lopez AD. Global health statistics: a compendium of incidence, prevalence and mortality estimates for over 200 conditions. Harvard School of Public Health, Boston: Harvard University Press, 1996.

2 Jacobs GD, Sayer I. Road accidents in developing countries. Accid Anal Prev 1983;15:337-53.

3 Department of the Environment, Transport and the Regions. Road accidents Great Britain 1996. London: The Stationery Office, 1997.

4 Hillman M, Adams J, Whitelegg J. One false move: a study of children's Hillman M, Adams J, Whitelegg J. One false move: a study
independent mobility. London: Policy Studies Institute, 1991.

5 Roberts I, Hollis S, Campbell F, Yates D. Declining injury rates for children and young adults: the contribution of hospital care. BMf 1996;313:1239and 41 .
6 Murray CJL, Lopez AD. Alternative projections of mortality and disability by cause 1990-2020: global burden of disease study. Lancet 1997;349: 1498-504

7 Chalmers I, Altman DG, eds. Systematic reviews. London: BMJ Publishing Group, 1995.

8 Peek-Asa C. The effect of random alcohol screening in reducing motor vehicle crash injuries. Am f Prev Med 1999;16(1 suppl):57-67.

9 Thompson DC, Rivara FP. Pool fencing for preventing drowning in children (Cochrane Review). The Cochrane Library, Issue 1, 1999. Oxford: Update Software.

10 The Cochrane Injuries Group Albumin Reviewers. Human albumin solution for resuscitation and volume expansion in critically ill patients (Cochrane review). The Cochrane Library, Issue 1, 1999. Oxford: Update Software.

11 Peto R, Collins R, Gray R. Large-scale randomised evidence: large simple trials and overviews of trials. $\mathcal{F}$ Clin Epidemiol 1995;48:23-40.

12 Donner A. Some aspects of the design and analysis of cluster randomised trials. Appl Statist 1998;47:95-113.

13 Ad Hoc Committee on Health Research Relating to Future Intervention Options. Investing in health research and development. Geneva: World Health Organisation, 1996.

14 Viner R. Politics, power and paediatrics. Lancet 1999;353:232-4

15 House of Commons official report (Hansard) Road Traffic Reduction (United Kingdom Targets) Bill. 30 Jan 1998: Column 621. 